\title{
Desempenho de cultivares de cebola nos sistemas orgânico e convencio- nal em Minas Gerais
}

\author{
Gabriel Belfort Rodrigues; Pâmela G Nakada; Derly JH da Silva; Gustavo G Dantas²; Ricardo RH Santos \\ UFV, Dep ${ }^{\text {to }}$. Fitotecnia, 36571-000 Viçosa-MG; derly@ mail.ufv.br
}

\section{RESUMO}

O presente trabalho teve como objetivo avaliar o desempenho de 16 cultivares de cebola nos sistemas orgânico e convencional em Viçosa-MG, de abril a dezembro de 2003. As cultivares avaliadas foram Texas Early Grano, Baia Periforme, Alfa Tropical, Texas Yellow Grano, Jubileu, Crioula do Alto Vale, Encino, Régia, Tropical Valley, Serrana, Bella Crioula, Ipa-6, Bola Precoce e os híbridos Granex, Mercedes e Baia Dura. Foram realizados dois experimentos, um em área de cultivo convencional e outro em área de cultivo orgânico, em blocos ao acaso com quatro repetições e 20 plantas por parcela. Foram avaliadas as seguintes características: produtividade, bulbificação, peso de bulbos, perda de peso e o teor de sólidos solúveis. As cvs. Texas Early Grano, Régia, Mercedes e Encino foram as que apresentaram maior perda de peso. O sistema convencional proporcionou maior instabilidade para as outras características e somente para o teor de sólidos solúveis esteve associado à média alta. No entanto, para todas as características a média das melhores cultivares do sistema convencional foi maior do que as melhores cultivares no sistema orgânico. As cvs. Baia Dura, Bola Precoce e Tropical Valley apresentaram maior produtividade e maior potencial à industrialização devido à maior bulbificação, maior peso de bulbo e maior teor de sólidos solúveis apresentado no sistema convencional.

Palavras-chave: Allium cepa L., agricultura alternativa.

\begin{abstract}
Performance of onion cultivars grown in the organic and conventional systems in Minas Gerais State, Brazil

The performance of sixteen onion cultivars grown in the organic and conventional systems was evaluated in Viçosa, Minas Gerais State, Brazil, from April to December 2003. The following onion cultivars were evaluated: 'Texas Early Grano', 'Baia Periforme', 'Alfa Tropical', 'Texas Yellow Grano', 'Jubileu', 'Crioula do Alto Vale', 'Encino', 'Régia', 'Tropical Valley', 'Serrana', 'Bella Crioula', 'Ipa-6', 'Bola Precoce' and the hybrids 'Granex', 'Mercedes' and 'Baia Dura'. Two experiments were carried out, one in an area of conventional cultivation and another in an organic area, in a randomized block design with four replicates (20 plants per plot). The following characteristics were evaluated: yield, bulbing, bulb weight, bulb weight loss and soluble solids. Four cultivars ('Texas Early Grano', 'Régia', 'Mercedes' and 'Encino') showed highest bulb weight loss, ranging from $5.58 \%$ to $6.81 \%$ after 30 days of harvest; other cultivars showed bulb weight loss ranging from 1,99\% (cv. Serrana) to $4,71 \%$ (cv. Granex). Nine cultivars had higher yield in the conventional system (cvs. Alfa Tropical, Serrana, Bola Precoce, Baia Dura, Baia Periforme, Bella Crioula, Tropical Valley, Jubileu and Crioula do Alto Vale) compared to the organic system. Cvs. 'Baia Dura', 'Bola Precoce' and 'Tropical Valley' grown in the conventional system had higher yields and showed potential for industrialization, mainly because of bulb quality, higher bulb average weight and soluble solids content.
\end{abstract}

Keywords: Allium cepa L., alternative agriculture.

(Recebido para publicação em 8 de outubro de 2005; aceito em 5 de junho de 2006)

A cebola é consumida in natura e desidratada principalmente devido ao seu sabor, aroma e pungência (Kopsell \& Randle, 1997). A pungência conferida pelo ácido pirúvico é maior quanto maior o teor de sólidos solúveis (Moretti \& Durigan, 2002). Além disso, o teor de sólidos solúveis tem correlação positiva com o conteúdo de matéria seca e açúcares redutores. O conteúdo de matéria seca é um importante fator de qualidade, principalmente para a indústria de processamento. Quanto maior o teor de matéria seca, menor é a quantidade de energia exigida para o processo de desidratação (Soares et al., 2004). O conteúdo de açúcares redutores determina a intensidade das reações responsáveis pelo escurecimento do produto final e a perda de peso (Moretti \& Durigan, 2002).

A quantidade e qualidade de cebola produzida é função da aplicação de nitrogênio, da irrigação, da época de colheita, da cultivar e do sistema de cultivo (Kopsell \& Randle, 1997). O excesso de nitrogênio e de irrigação diminui o teor de sólidos solúveis e o tempo de armazenamento, sendo a quantidade dessa mudança função da cultivar (Uzo \& Currah, 1990; Gamiely et al., 1991). A antecipação da colheita em 15 dias não afetou a produção nas cultivares Granex, Baia Periforme e Jubileu, mas diminuiu o teor de sólidos solúveis na cultivar Baia Periforme (Soares et al., 2004). O teor de sólidos solúveis varia em função da cultivar (Rutherford \&
Wittle, 1982). Kopsell \& Randle (1997) sugerem a necessidade de cultivares específicos ao consumo in natura e para a indústria de processamento.

O sistema orgânico para o cultivo de cebola ainda não é uma realidade (Vidigal et al., 2002), mas pode ser factível desde que se disponha de material orgânico suficiente para fornecer todos os nutrientes necessários para o crescimento das plantas. Gonçalves \& Silva (2003) sugerem ser possível substituir a adubação de origem mineral pela orgânica com conseqüências na produção e qualidade do produto obtido. Não existem relatos disponíveis sobre o desempenho de diferentes cultivares de cebola nos dois sistemas de cultivo ou mesmo de sua interação. Atualmente a 
utilização de um sistema mais sustentável é uma exigência da sociedade. No entanto, essa sustentabilidade deve proporcionar uma produção quantitativa e qualidade da cebola. O presente trabalho teve como objetivo avaliar o efeito do sistema de cultivo na produção de diferentes cultivares de cebola.

\section{MATERIAL E MÉTODOS}

O ensaio foi conduzido na Horta de Pesquisa do Departamento de Fitotecnia da Universidade Federal de Viçosa no período de 7 de abril a 19 de dezembro de 2003 em Viçosa. Foram selecionadas dezesseis cultivares de cebola, sendo sete de dias curtos (=DC): cvs. Texas Early Grano, Alfa Tropical, Texas Yellow Grano, Régia, Serrana, Ipa-6 e Granex; quatro cultivares de dias intermediários (=DI): Baia Periforme, Bella Crioula, Bola Precoce, Mercedes e Baia Dura; e quatro cultivares de dias longos (=DL): Crioula do Alto Vale, Encino, Tropical Valley e Jubileu.

As dezesseis cultivares foram plantadas em dois experimentos, um conduzido em sistema convencional e o outro em sistema orgânico. Utilizou-se o método de produção de cebola por mudas, produzidas em canteiros de $10 \mathrm{~m}^{2}$, com $0,15 \mathrm{~m}$ de altura. O substrato foi uma mistura de duas partes de solo, uma parte de esterco e uma parte de areia. As sementes foram plantadas em sulcos espaçados $0,10 \mathrm{~m}$ e com $0,02 \mathrm{~m}$ de profundidade, na densidade de $2 \mathrm{~g} / \mathrm{m}^{2}$ (Boff \& Debarba, 1999). Aos 57 dias após a semeadura, quando as plantas atingiram $15 \mathrm{~cm}$ de altura e $0,6 \mathrm{~cm}$ de diâmetro (Fontes \& Silva, 2002), as mudas foram transplantadas. Para esta fase, utilizouse quatro canteiros de $1 \mathrm{~m}$ de largura e $0,15 \mathrm{~m}$ de altura em cada experimento, com quatro linhas espaçadas de $0,2 \mathrm{~m}$ e com 19,2 m de comprimento e espaçamento na linha de $0,10 \mathrm{~m}$ entre plantas. O delineamento experimental utilizado foi blocos ao acaso com quatro repetições, sendo cada canteiro um bloco e a parcela experimental constituída por 20 plantas.

O plantio do experimento em sistema convencional foi em área previamente cultivada com hortaliças, sendo a adubação feita de acordo com a análise de solo (Fontes, 1999) e o controle de pragas e doenças com inseticidas e fungicidas recomendados para a cultura (Brasil, 2002). As doenças que necessitaram de manejo durante a condução do experimento foram: míldio (Peronospora destructor), mancha púrpura (Alternaria porri) e ferrugem da cebola (Puccinia porri). As pulverizações para controle das doenças foram realizadas tão logo foram identificadas no campo. O tripes (Thrips tabaci) foi a única praga observada, sendo adotado 20 adultos por planta como o nível de controle, com amostragem semanal em cinco plantas por bloco (Picanço et al., 2000). O manejo das plantas daninhas foi mecânico, e a irrigação foi feita de acordo com as recomendações para a cultura (Filgueira, 2000).

No experimento em sistema orgânico, o plantio foi realizado em área de produção de hortaliça conduzida de modo alternativo há quatro anos. A adubação consistiu da aplicação de composto orgânico na dose de $3 \mathrm{~kg} / \mathrm{m}^{2}$ de matéria fresca (Souza, 1998), que no presente caso equivaleu a $1,75 \mathrm{~kg} / \mathrm{m}^{2}$ de matéria seca. A composição química do composto apresentou os seguintes teores (em $\mathrm{g} / \mathrm{kg}$ de matéria seca): $\mathrm{P}=33 ; \mathrm{Ca}=134$; $\mathrm{Mg}=8 ; \mathrm{K}=5 ; \mathrm{S}=17 ; \mathrm{Al}=27 ; \mathrm{Fe}=23$; $\mathrm{Mn}=1 ; \mathrm{Zn}=0,4 ; \mathrm{B}=0,01 ; \mathrm{Cu}=0,06 ; \mathrm{Ni}=$ 0,$05 ; \mathrm{Cr}=0,07$. Outras características: $\mathrm{N}=2,85 \% ; \mathrm{C} / \mathrm{N}=20,51 ; \mathrm{C}$ total $=$ $58,46 \%$; $\mathrm{C}-\mathrm{HU}=24,73 \%$; $\mathrm{C}-\mathrm{AH}=$ $7,78 \%$. Foi realizada uma adubação de cobertura com $50 \mathrm{~g} / \mathrm{m}^{2}$ com esterco de galinha curtido e $20 \mathrm{~g} / \mathrm{m}^{2}$ de cinza.

No manejo fitossanitário para o sistema orgânico foram utilizadas as caldas bordalesa e sulfocálcica (Abreu Junior, 1998), sendo a calda bordalesa empregada para o controle de míldio e da mancha púrpura e a calda sulfocálcica para a ferrugem e tripés. O controle das doenças e pragas, o manejo das plantas daninhas e a irrigação foram os mesmos adotados para o sistema convencional. As doenças e as pragas nos dois experimentos foram manejadas até que 50\% das plantas dos dois experimentos estavam "estaladas", sendo este o momento em que a irrigação foi cortada.

O ponto de colheita foi aos 139 dias após o plantio das mudas, quando havia $80 \%$ das plantas estaladas (Soares et al.,
2004). Após a colheita os bulbos foram armazenados em estrados de bambu sob galpão. Foram avaliadas as seguintes características: produtividade: produção de matéria fresca de bulbos por unidade de área em t/ha; bulbificação: número de plantas que produziram bulbos; peso médio dos bulbos produzidos, em g/bulbo; perda de peso: diferença de peso dos bulbos entre 15 e 30 dias após a colheita; teor de sólidos solúveis: determinado em dois bulbos por parcela aos 30 dias após a colheita. O material extraído para a determinação de sólidos solúveis foi obtido por meio de pressão na metade inferior dos bulbos após o corte transversal na região mediana e leitura em refratômetro do tipo 'Q 107D145'.

Os dados de cada experimento foram submetidos à análise de normalidade de Kolmogorov-Smirnov (Steel et al., 1997). Constada normalidade os dados foram submetidos ao teste de homogeneidade das variâncias pelo teste de Bartlett (Ramalho et al., 2000). Então se realizou a análise de variância (ANOVA) conjunta (Cruz \& Regazzi, 2001). Quando significativo na ANOVA, somente o fator cultivares foi submetido ao teste de grupamento de Scott Knott (5\% de probabilidade).

\section{RESULTADOS E DISCUSSÃO}

O desempenho das cultivares foi coincidente entre os sistemas de cultivo para a perda de peso aos 30 dias após a colheita, ou seja, a interação cultivares por sistemas de cultivo não foi significativa na ANOVA $(\mathrm{p}<0,05)$. No entanto, constatou-se diferença entre as cultivares, que foram separadas em dois grupos em relação a esta característica. Quatro cultivares apresentaram maior perda de peso: cv. Texas Early Grano, 6,81\%; cv. Encino, 6,69\%; cv. Régia, 6,58\%; e cv. Mercedes, 5,58\%. As demais variaram de $1,99 \%$ (cv. Serrana) a 4,71\% (cv. Granex). Aparentemente, a perda de peso é uma característica intrínseca da cultivar, não sendo função somente da exigência de fotoperíodo para a bulbificação (Kopsell \& Randle, 1997).

Para produtividade, bulbificação, peso de bulbo e sólidos solúveis o desempenho das cultivares dependeu do sistema de cultivo (ANOVA, p<0,05). 
Tabela 1. Produtividade (t/ha) bulbificação ( ${ }^{\circ}$ de plantas), peso de bulbos (g) e sólidos solúveis ( ${ }^{\circ}$ Brix) de cultivares de cebola conduzidas em sistema convencional e orgânico. Viçosa, UFV, 2003.

\begin{tabular}{|c|c|c|c|c|c|c|c|c|}
\hline \multirow{2}{*}{ Cultivar* } & \multicolumn{2}{|c|}{ Produtividade (t/ha) } & \multicolumn{2}{|c|}{$\begin{array}{c}\text { Bulbificação (no } \\
\text { plantas) }\end{array}$} & \multicolumn{2}{|c|}{ Peso bulbo (g) } & \multicolumn{2}{|c|}{ Sólidos solúveis ( ${ }^{\circ} \mathrm{Brix}$ ) } \\
\hline & Convenc. & Orgânico & Convenc. & Orgânico & Convenc. & Orgânico & Convenc. & Orgânico \\
\hline Tropical Valley (DL) & $50,53 a^{* *}$ & $36,09 \mathrm{~b}$ & $19,00 \mathrm{a}$ & $19,00 \mathrm{~b}$ & $107,10 \mathrm{a}$ & $75,75 \mathrm{~b}$ & $9,48 a$ & 9,03 a \\
\hline Bola Precoce (DI) & 51,85 a & $36,09 \mathrm{~b}$ & $20,00 \mathrm{a}$ & $20,00 \mathrm{a}$ & $103,70 \mathrm{a}$ & $73,40 \mathrm{~b}$ & $10,55 \mathrm{a}$ & 9,38 a \\
\hline Híbrido Baia Dura (DI) & 50,60 a & $30,77 \mathrm{~b}$ & 19,75 a & $17,75 b$ & 102,48 a & $70,13 \mathrm{~b}$ & $10,10 \mathrm{a}$ & $10,33 a$ \\
\hline Régia (DC) & $40,75 \mathrm{~b}$ & $40,79 a$ & $17,50 \mathrm{a}$ & $18,25 \mathrm{~b}$ & 92,28 a & $88,50 \mathrm{a}$ & $7,73 \mathrm{~b}$ & $5,65 b$ \\
\hline Alfa Tropical (DC) & $36,45 b$ & 29,82 b & $19,25 \mathrm{a}$ & $18,25 \mathrm{~b}$ & 75,65 a & $64,85 \mathrm{c}$ & $8,63 \mathrm{~b}$ & $11,73 a$ \\
\hline Jubileu (DL) & $40,78 b$ & $25,28 \mathrm{c}$ & 19,75 a & $19,75 a$ & 82,68 a & $58,60 \mathrm{c}$ & $10,20 \mathrm{a}$ & 9,85 a \\
\hline Híbrido Granex (DC) & $21,78 \mathrm{c}$ & $41,39 \mathrm{a}$ & $18,00 \mathrm{a}$ & $19,25 \mathrm{a}$ & $48,98 \mathrm{~b}$ & 86,05 a & $6,95 \mathrm{~b}$ & $5,80 \mathrm{~b}$ \\
\hline Híbrido Mercedes (DI) & $13,03 \mathrm{c}$ & $50,52 \mathrm{a}$ & $14,25 \mathrm{~b}$ & $20,00 \mathrm{a}$ & $37,25 \mathrm{~b}$ & $101,03 \mathrm{a}$ & $6,95 \mathrm{~b}$ & $5,75 b$ \\
\hline Ipa-6 (DC) & $13,70 \mathrm{c}$ & $31,07 \mathrm{~b}$ & $18,75 \mathrm{a}$ & $20,00 \mathrm{a}$ & $29,18 \mathrm{~b}$ & $54,65 \mathrm{c}$ & 9,78 a & $10,18 a$ \\
\hline Baia Periforme (DI) & $22,33 \mathrm{c}$ & $10,97 d$ & $20,00 \mathrm{a}$ & $19,75 \mathrm{a}$ & $44,65 \mathrm{~b}$ & $22,15 d$ & $7,10 \mathrm{~b}$ & $9,70 \mathrm{a}$ \\
\hline Bella Crioula (DI) & $16,70 \mathrm{c}$ & $8,10 \mathrm{~d}$ & $19,25 \mathrm{a}$ & $20,00 \mathrm{a}$ & $34,98 \mathrm{~b}$ & $12,13 d$ & 11,43 a & $10,43 a$ \\
\hline Texas Early Grano (DC) & $4,28 d$ & $22,59 \mathrm{c}$ & $14,75 \mathrm{~b}$ & $19,00 \mathrm{~b}$ & $10,53 \mathrm{c}$ & $47,28 \mathrm{c}$ & $7,98 \mathrm{~b}$ & $4,65 b$ \\
\hline Texas Yellow Grano (DC) & $1,83 \mathrm{~d}$ & $21,83 c$ & $9,25 \mathrm{c}$ & $18,25 \mathrm{~b}$ & $18,25 \mathrm{c}$ & $47,63 \mathrm{c}$ & $0,00^{* *}$ & $5,33 \mathrm{~b}$ \\
\hline Encino (DL) & $4,00 \mathrm{~d}$ & $21,00 \mathrm{c}$ & $9,75 \mathrm{c}$ & $18,25 \mathrm{~b}$ & $12,10 \mathrm{c}$ & $45,85 \mathrm{c}$ & $6,18 \mathrm{~b}$ & $5,03 b$ \\
\hline Crioula do Alto Vale (DL) & $9,70 \mathrm{~d}$ & $6,98 \mathrm{~d}$ & $19,75 \mathrm{a}$ & $20,00 \mathrm{a}$ & $19,68 \mathrm{c}$ & $13,98 d$ & $11,23 \mathrm{a}$ & 9,53 a \\
\hline Serrana (DC) & $11,03 d$ & $6,03 \mathrm{~d}$ & $18,25 \mathrm{a}$ & $20,00 \mathrm{a}$ & $24,25 \mathrm{c}$ & $9,08 \mathrm{~d}$ & $11,53 \mathrm{a}$ & $10,43 \mathrm{a}$ \\
\hline Média & 24,27 & 26,03 & 17,33 & 19,22 & 52,73 & 54,44 & 8,39 & 7,99 \\
\hline $\mathrm{C}, \mathrm{V},(\%)$ & 28,69 & 24,98 & 10,53 & 4,39 & 28,81 & 27,22 & 8,39 & 7,99 \\
\hline
\end{tabular}

*Cultivares: $\mathrm{DL}=$ dias longos; $\mathrm{DI}=$ dias intermediários; $\mathrm{DC}=$ dias curtos; **As médias seguidas pela mesma letra na coluna pertencem ao mesmo grupo de médias pelo teste de Scott Knot a $5 \%$ de probabilidade.

No cultivo convencional, as cultivares foram separadas em quatro grupos de médias, sendo as maiores produtividades observadas para as cvs. Bola Precoce, Baia Dura e Tropical Valley (Tabela 1). Para o sistema orgânico, também observou-se quatro grupos, mas as melhores foram as cvs. Granex, Régia e Mercedes (Tabela 1).

Das 16 cultivares avaliadas, nove apresentaram produtividade superior no sistema convencional em relação ao sistema orgânico (cvs. Alfa Tropical, Serrana, Bola Precoce, Baia Dura, Baia Periforme, Bella Crioula, Tropical Valley, Jubileu e Crioula do Alto Vale). O cultivo convencional teve menor média geral e maior instabilidade da produtividade, ou seja, maior coeficiente de variação (C.V.). Constatou-se que o sistema de cultivo convencional propicia condições mais instáveis para as cultivares. A média das melhores cultivares no sistema convencional $(50,99 \mathrm{t} / \mathrm{ha})$ foi maior que a média das melhores cultivares no sistema orgânico (44,23 t/ha).

As cultivares foram divididos em três grupos de bulbificação no sistema convencional, sendo as melhores as cvs. Régia, Alfa Tropical, Granex, Ipa-6,
Serrana, Bola Precoce, Bella Crioula, Baia Periforme, Baia Dura, Tropical Valley, Crioula do Alto Vale e Jubileu (Tabela 1). No cultivo orgânico, foi observado dois grupos, sendo as melhores as cvs. Granex, Ipa-6, Serrana, Bella Crioula, Baia Periforme, Mercedes, Bola Precoce, Jubileu e Crioula do Alto Vale. Três cultivares (Bola Precoce, Tropical Valley e Jubileu) apresentaram a mesma bulbificação nos dois sistemas de cultivo. Outras três (cvs. Alfa Tropical, Baia Dura e Baia Periforme) bulbificaram melhor no cultivo convencional. No entanto, dez cultivares tiveram maior bulbificação no sistema orgânico (cvs. Régia, Granex, Ipa-6, Texas Early Grano, Texas Yellow Grano, Serrana, Mercedes, Bella Crioula, Crioula do Alto Vale e Encino). A bulbificação é determinada pela cultivar, fotoperíodo, idade fisiológica da planta, irrigação e concentração de nitrogênio. Este último é o único fator que varia entre os sistemas de cultivo. Portanto, a menor bulbificação no sistema convencional é devido ao manejo do nitrogênio, que aumenta a produção de bulbos com "pescoço grosso" ou "charuto" (Brewster \& Butler, 1989). Além disso,
Rodrigues \& Casali (1998) indicam que o composto orgânico contribui para a melhoria das condições físicas do solo, que melhora a bulbificação.

As cultivares Régia, Alfa Tropical, Bola Precoce, Baia Dura, Tropical Valley e Jubileu apresentaram maiores peso de bulbo no sistema convencional (Tabela 1). No cultivo orgânico, as cvs. Régia, Granex e Mercedes foram as que apresentaram maior peso de bulbo. No sistema convencional, dez cultivares apresentaram maior peso médio de bulbo quando comparadas com o sistema orgânico. No entanto, o peso médio de bulbo do sistema convencional foi menor, com maior C.V., ou seja, o sistema convencional propiciou menor estabilidade para peso de bulbo do que o sistema orgânico. A média das melhores cultivares no sistema convencional $(93,28$ $\mathrm{g} / \mathrm{bulbo}$ ) é maior do que a média das melhores cultivares no sistema orgânico (91,86 g/bulbo). Portanto, se fossem selecionadas as melhores cultivares para cada sistema, aquelas do cultivo convencional apresentariam maior peso de bulbo do que o cultivo orgânico.

Para sólidos solúveis, observou-se três diferentes grupos no sistema con- 
vencional, sendo que as melhores cultivares foram Ipa-6, Serrana, Bella Crioula, Baia Dura, Bola Precoce, Crioula do Alto Vale, Jubileu e Tropical Valley (Tabela 1). No cultivo orgânico, foram observados dois grupos para sólidos solúveis, e as cvs. Alfa Tropical, Serrana, Ipa-6, Bola Precoce, Baia Dura, Baia Periforme, Bella Crioula, Crioula do Alto Vale, Tropical Valley e Jubileu apresentaram os teores mais altos. Em $68,75 \%$ das cultivares, o teor de sólidos solúveis foi maior no sistema convencional. O C.V. também foi mais alto para essa característica no sistema convencional, mas com média mais alta do que no sistema orgânico. A média das melhores cultivares do sistema convencional $(10,54 \%)$ também foi maior do que a média das melhores cultivares no sistema orgânico $(10,06 \%)$. Portanto, o rendimento para a industrialização é melhor no sistema convencional, pois é possível obter bulbos com maior conteúdo de matéria seca e menor problema com coloração (Moretti \& Durigan, 2002; Soares et al., 2004). A diferença observada no teor de sólidos solúveis entre os sistemas de cultivo não causou diferença na perda de peso dos bulbos, e deduziu-se que a perda de peso dependeu apenas da cultivar.

O cultivo convencional apresentará maior produtividade e maior potencial à industrialização com as cultivares Baia Dura, Bola Precoce e Tropical Valley devido principalmente à maior bulbificação, maior peso de bulbo e maior teor de sólidos solúveis apresentado no sistema convencional para estas cultivares.

\section{REFERÊNCIAS}

ABREU JUNIOR H. 1998. Práticas alternativas de controle de pragas e doenças na agricultura. 1. ed. Campinas: EMOPI.

BOFF P; DEBARBA JF. 1999. Tombamento e vigor de mudas de cebola em função de diferentes profundidades e densidades de semeadura. Horticultura Brasileira 17: 15-19.

BRASIL. Ministério da agricultura, Pecuária e Abastecimento. 2003, 13 março. Controle de pragas e doenças. Disponível em http:// www.masrv60.agricultura.gov.br/agrofit/ Agrofit

BREWSTER JL; BUTLER HA. 2001. Effects of nitrogen supply on development in onion Allium cepa L.. Journal of Experimental Botany 40: 1155-1162.

CRUZ CD; REGAZZI AJ. 2001. Modelos biométricos aplicados ao melhoramento genético. 2. ed. Viçosa: UFV. 390p.

FILGUEIRAFAR. Novo manual de Olericultura: Agrotecnologia moderna na produção $e$ comercialização de hortaliças. Viçosa: Editora UFV. 402p.

FONTES PCR. 1999. Adubação de culturas hortícolas: $5^{a}$ aproximação. Viçosa: Comissão de fertilidade do solo do Estado de Minas Gerais. 359p.

FONTES PCR; SILVA DJH. 2002. Métodos de produção de cebola. Informe Agropecuário 286: 30-34

GAMIELY S; RANDLE WM; MILLS HA; SMITTLE DA; BANNA GI. 1991. Onion plant growth, bulb quality, and water uptake following ammonium and nitrate nutrition. HortScience 26: 1061-1063.

GONÇALVES PAS; SILVA CRS. 2003. Impacto da adubação orgânica sobre a incidência de tripes em cebola. Horticultura Brasileira 21: 459-463.

KOPSELL DE; RANDLE WM.1997. Onion cultivars differ in pungency and quality changes during storage. HortScience 32: 12601263.
MATSON PA; PARTON WJ; POWER AG; SWIFT MJ. 1997. Agricultural intensification and proprieties. Science 277: 504-509.

MORETTI CL; DURIGAN JF. 2002. Processamento de cebola. Informe Agropecuário 286: 9-104.

PAULA JUNIOR TJ; MORANDI MAB; ZAMBOLIM L; SILVA MB. 2002. Controle alternativo de doenças de plantas-Histórico. In: VENZON M; PAULA JUNIOR TJ; PALLINI A (eds). Controle alternativo de pragas e doenças. Viçosa: EPAMIG/UFV. p. 135-162.

PICANÇO M; GUSMÃO MR; GALVAN TL. 2000. Manejo integrado de pragas de hortaliças. In: Manejo integrado de doenças, pragas e plantas daninhas. Viçosa: UFV. p. 283.

RAMALHO MAP; FERREIRA DF; OLIVEIRA AC. 2000. Experimentação em genética e melhoramento de plantas. Lavras: UFLA. p. 326

RODRIGUES ET; CASALI VWD. 1998. Respostas da alface à adubação orgânica. 2 teores, conteúdos e utilização de macronutrientes em cultivares. Revista Ceres 45: 437-449.

RUTHERFORD PP; WHITTLE R. 1984. Methods of predicting the long-term storage of onions. Journal of Horticultural Science 59: 537-543.

SOARES VLF; FINGER FL; MOSQUIM PR. 2004. Influência do genótipo e do estádio de maturação na colheita sobre a matéria fresca, qualidade e cura dos bulbos de cebola. Horticultura Brasileira 22: 18-22.

SOUZA LJ. 1998. Agricultura orgânica: tecnologias de alimentos saudáveis. vol. I, Ed. Gráfica e Encadernadora Sodré Ltda. p.19.1998.

STEEL RGD; TORRIE JH; DICKEY DA. 1997. Principles and procedures of statistics: a biometrical approach. 3. ed. New York: McGraw-Hill. 666p.

UZO JO; CURRAH L. 1990. Cultural systems and agronomic practices in tropical climates, In: RABINOWITCH HD; BREWSTER JL (eds). vol. 2. Onions and allied crops. CRC Press Boca Raton. p. 49-52.

VIDIGAL SM; PEREIRA PRG; PACHECO DD. 2002. Nutrição mineral e adubação da cebola. Informe Agropecuário 286: 46. 